\title{
OBTENÇÃO DE FILMES DECORATIVOS PARA O DESIGN DE JOIAS
}

\author{
Luciane Calabria \\ Centro Universitário da Serra Gaúcha \\ Luiza Grazziotin Selau \\ Centro Universitário da Serra Gaúcha \\ Elis Fachin Comerlato \\ Centro Universitário da Serra Gaúcha
}

\begin{abstract}
Resumo: O Brasil apresentou dados crescentes referentes à produção e comercialização de joias de ouro e de prata, sendo o estado do Rio Grande do Sul um dos mais importantes colaboradores para a expansão do setor. Foram analisadas empresas gaúchas joalheiras que produzem joias a partir de materiais nobres e apresentam significativas possibilidades de crescimento, a análise levou em conta as funções que a joia desempenha através de suas representações pessoais, sociais e culturais. O estudo revelou que o design atua como um importante aliado na competitividade das empresas e que há uma oportunidade crescente no desenvolvimento de joias autênticas contemporâneas para os consumidores que buscam produtos com qualidade, inovação, diferenciação e que representem a individualidade do usuário. Para tal, novos processos de fabricação e o estudo de novos materiais apresentam potencial para este setor, com isso o processo de Deposição Física de Vapor (PVD) se torna atrativo, pois além de ser um processo rápido podendo se obter uma numerosa gama de filmes decorativos, tem-se uma abordagem com viés sustentável, devido ao processo ser considerado limpo.
\end{abstract}

Palavras-chave: Inovação, design, materiais, deposição física de vapor, joias.

Abstract: Brazil showed the growing data on the production and sale of gold jewelry and silver, and the south Brazil one of the most important contributors to the expansion of the sector. Jewelry local companies were analyzed to produce jewelry from fine materials and have significant growth potential, the analysis took into account the functions that gem plays through their personal, social and cultural representations. The study revealed that the design serves as an important ally in the competitiveness of companies and there is a growing opportunity in the development of contemporary authentic jewelry to consumers who seek products with quality, innovation, differentiation and representing the individuality of the user. For this new manufacturing processes and the study of new materials have the potential for this sector, so the process of Physical Vapor 
Deposition (PVD) becomes attractive, as well as being a quick process can obtain a large range of decorative films We have an approach to sustainable bias due to the process to be considered clean.

Keywords: Innovation, design, materials, physical vapor deposition, jewelry.

\section{INTRODUÇÃO}

No design, a competitividade envolve aspectos referentes à funcionalidade, à ergonomia, ao conforto, à facilidade de uso e à durabilidade que contribuem agregando valor ao produto. Outros fatores produtivos como, por exemplo, a escolha dos materiais também são determinantes para valorização de um artefato, a adequação do produto ao usuário, muitas vezes, pode estar relacionada à origem dos materiais. A utilização coerente dos materiais pode facilitar o manuseio do objeto e as percepções estéticas, simbólicas e de operação por parte do usuário.

Na confecção de uma peça de joalheria, também devem ser considerados os fatores ergonômicos, proporcionando da melhor maneira, a máxima adequação do produto ao usuário. Os anéis, por exemplo, não devem interferir no manejo dos objetos ou ocasionar qualquer tipo de desconforto ao usuário. Os brincos devem possuir pesos adequados para que os lóbulos das orelhas não sejam danificados. Já as correntes e pulseiras devem possuir fechos que garantam a fácil compreensão e utilização proporcionando segurança e firmeza no momento da colocação da peça.

No presente estudo, observa-se também que as joias apresentam informações sobre as marcas e os materiais empregados, que localizam-se principalmente no interior dos anéis. Essas informações garantem a qualidade dos produtos e ressaltam a importância das marcas aos consumidores.

Portanto, pode-se concluir que o design agrega valor às joias em decorrência de aspectos que envolvem a funcionalidade, a ergonomia, o conforto, a qualidade, a facilidade de uso, a estética e os aspectos simbólicos que são percebidos de forma imediata pelo consumidor no momento da compra e no ato da utilização do produto.

\section{DESIGN PARA INOVAÇÃO}

O que dá essência ao design é a inovação. É através do design que se definem as características formais dos produtos, agregando valores durante o processo de criação, fazendo com que se tornem diferenciados, atraentes e eficientes e com que correspondam às expectativas e satisfaçam as necessidades daqueles que se identificarão visualmente com o objeto. (HENRIQUES, 2015) O designer é apto a designar novos conceitos para diversos e diferentes projetos. O produto resultante do processo projetual tem o objetivo de satisfazer as necessidades e os desejos dos usuários. (LESKO, 2004)

Cabe ao designer de produto a responsabilidade da estrutura formal do objeto, mas também é de extrema importância que o designer compreenda os processos de fabricação existentes a fim de tornar o projeto adequado às necessidades dos usuários e mais econômico industrialmente (NEGRÃO, 2008). O designer qualificado é aquele 
que entende as necessidades, desejos, valores e expectativas dos usuários. Os usuários geralmente são conservadores e só adquirem novos produtos se realmente existirem vantagens em relação a outros produtos. Portanto, os novos produtos devem ser direcionados para o consumidor (BAXTER, 2011).

O processo de desenvolvimento de produtos agrega ao designer um amplo conhecimento referente às necessidades mercadológicas, criação de novos produtos, novos materiais, outras formas de utilização de materiais conhecidos, funcionalidade por meio de tecnologia e, principalmente, o designer acaba desvendando diversas formas de atrair o consumidor. (MORRIS, 2010) O design precisa inovar, mas sem perder os vínculos com a realidade, fazendo parte da simbologia, composição material e dos relacionamentos e atividades da sociedade (ONO, 2015).

Joia é um objeto usado junto ao corpo que possui como principal função adornar e realçar a estética de quem as utiliza. As joias geralmente são confeccionadas com materiais extraídos da natureza como metais nobres e/ou gemas, denominadas pedras preciosas. O trabalho na joalheria é cheio de detalhes, com uma qualidade técnica imensurável, tornando visíveis os aspectos estéticos da peça e agregando valor ao produto. (STRALIOTTO, 2015) A área de atuação de design de joias é responsável pelo desenvolvimento de produtos industriais envolvendo peças de joalheria, incluindo bijuterias e peças folhadas. (GOMES FILHO, 2006) O trabalho de joalheria exige um constante exercício de criatividade. E para que os resultados desejados sejam alcançados satisfatoriamente, é necessária uma harmonia de formas e volumes aliada a exploração de materiais e técnicas. (PRENDINI, 2013)

O design de joias está sempre em busca de aprimoramento e qualidade através de novas tecnologias, metais, gemas, acabamentos, detalhes, conforto, estética e pesquisa para que, ao final, se consiga um produto com qualidade e diferenciação que satisfaçam o usuário e colabore com a prosperidade da indústria, tendo vista o crescimento constante do mercado joalheiro. (LISBÔA, 2009)

Com a evolução do segmento da joalheria, estão sendo criadas joias mais eficientes, criativas e com maior qualidade. No mercado atual cada vez mais surgem empresas nas áreas de serviços, indústria e comércio e empreendedores individuais. Também aparecem órgãos governamentais, associações e entidades que apoiam as atividades do setor joalheiro. (SANTOS, 2013) Atualmente a joia possui forte representação no mercado de trabalho envolvendo fornecedores, designers e comerciantes.

As funções das joias podem variar de acordo com a cultura onde está inserida. Sendo assim, podem ser definidas das seguintes maneiras: i) Como adorno: usadas principalmente junto ao corpo. São confeccionadas com materiais nobres como os metais e as gemas que agregam valores estéticos as joias. ii) Como portadora de valores: podem representar o poder e a riqueza material ao mesmo tempo em que representam a futilidade. Também podem transportar valores espirituais e mágicos referentes a determinadas culturas. iii) Como simbolismo religioso: as joias podem simbolizar crenças espirituais sendo utilizadas como objetos em rituais em diferentes culturas. iv) Como amuleto: pode ser utilizada como um objeto com propriedades "mágicas" contra doenças, espíritos, inveja, entre outros. O amuleto ou talismã possui 
a função de proteger o usuário de possíveis ameaças a sua vida. v) Como ornamento: objeto com valor artístico, com função estética e conceito de decoração. (GOLA, 2013)

Com as joias brasileiras em destaque no mercado internacional, houve um aumento da procura por profissionais especializados. Este fato é decorrente da valorização das gemas brasileiras após a década de 1990. (VICENTINI, 2015) Porém, nos últimos anos o setor joalheiro mundial está extremamente competitivo. Governos e empresas precisam inovar, estimulando e fortalecendo de maneira sustentável a capacidade de produção do país. (IBGM, 2015) A inovação é primordial para que se obtenha sucesso nos negócios. É importante para a economia que empresas sejam competitivas e que alcancem resultados maiores do que outras. Mas para que isso aconteça é necessário que sejam introduzidos novos produtos, impedindo que concorrentes adquiram a maior parte do mercado (BAXTER, 2011).

O design tem sido um aliado da competitividade da joia e da bijuteria brasileiras no mercado interno e externo. $O$ design brasileiro vem sendo cada vez mais identificado e reconhecido pelas cores, movimentos, alegria, diversidade e sensualidade que representam a brasilidade em produtos da moda. (PREVIEW DESIGN DE JOIAS E BIJUTERIAS, 2014)

\subsection{Metodologia de projeto}

O projeto descrito parte de metodologia projetual que visou primeiramente estudar o mercado nacional e gaúcho de produção de joias autênticas, as principais marcas, seus principais produtos e tendências de consumo. Ainda, objetivou-se a compreensão de quatro principais tópicos: a) Descrever as principais joias produzidas e comercializadas por grandes marcas gaúchas; b) Relacionar as joias estudadas com o perfil do seu público consumidor; c) Estudar a joia de alta joalheria como identidade cultural e representação social; d) Pesquisar as tendências e oportunidades no mercado para as joias brasileiras.

Diante dos objetivos apresentados e tópicos pesquisados, definiu-se a oportunidade de design encontrada onde, com a evolução e o aumento da competitividade no setor joalheiro, surgem cada vez mais joias criativas e com maior qualidade além da busca crescente por inovação. Sendo assim, percebeu-se que por meio do design seria possível propor um novo conceito de joias a partir de um método projetual de design, o qual busca atribuir valores estéticos e simbólicos, novas tecnologias, produtos diferenciados e que satisfaçam os desejos e as necessidades dos consumidores.

Levando em consideração o que já foi mencionado sobre o impacto do design na diferenciação entre joia e bijuteria brasileiras no sentido de proporcionar competitividade entre elas, ressalta-se que "O design brasileiro, ao possuir identidade, conceito e estilo próprios, vem sendo crescentemente reconhecido por sua alegria, cor, movimento, sensualidade e diversidade, que são atributos da brasilidade...". (HENRIQUES, 2014)

Sendo assim, o projeto foi norteado tendo como base uma metodologia projetual específica de design. Esta metodologia é dividida em quatro fases para que o processo de design possa ser desenvolvido, e visa gerar produtos industriais que possam satisfazer as necessidades humanas. As fases são: i) Fase de preparação: 
consiste basicamente na análise do problema, ou seja, é o conhecimento aprofundado do problema, coleta de informações e a análise dessas informações. Ao final deste processo chega-se a definição e clarificação do problema para assim definir os objetivos. ii) Fase de geração: é a fase de escolha dos métodos de design para solucionar o problema em questão. É nesta fase que são geradas as alternativas através de esboços de ideias e modelos. iii) Fase de avaliação: nesta fase as alternativas geradas são avaliadas através de um processo de seleção. A alternativa é escolhida conforme os objetivos de desenvolvimento do novo produto. iv) Fase de realização: é a fase de realização da alternativa escolhida. Nesta fase também é feita uma nova avaliação da solução e por fim são realizados projetos mecânicos e estruturais, configuração de detalhes, modelos, desenhos técnicos e de representação e documentações. (LÖBACH, 2001)

Além destas etapas, utilizou-se também as diretrizes com os oito tipos de inovação para o desenvolvimento de projetos que, obviamente, tem como objetivo ser inovadores. (BONSIEPE, 2011) As questões relacionadas à inovação em Design propostas por este autor são: inovação para melhorar a qualidade de uso de um produto; para criar; no processo de fabricação; na sustentabilidade; para facilitar o acesso; na implantação de novos materiais; na qualidade formal-estética e na oferta. Destas oito, trabalhou-se com quatro tipos de inovação, são elas: Inovação na sustentabilidade; Inovação na qualidade formal-estética; Inovação no processo de fabricação; Inovação na aplicação de novos materiais. Como resultado apresenta-se a Coleção Persona.

\subsubsection{Coleção Persona}

O mercado joalheiro estará extremamente competitivo em 2020. Assim, faz-se necessária a antecipação de mudanças e tendências pela indústria global para que estas se mantenham atualizadas de maneira a atender as expectativas dos consumidores. (IBGM, 2015)

A Coleção Persona representa a brasilidade através de suas formas inspiradas nas tradicionais máscaras de carnaval. As joias são portadoras do mistério, do luxo e da sofisticação que caracterizam o acessório carnavalesco e foram desenvolvidas para mulheres com personalidade marcante. Apresenta um novo conceito de joias contemporâneas através da inovação dos materiais e processos empregados na produção das peças.

No intuito de representar esta brasilidade, que expressa por meio de tantos detalhes características de um país tão diversificado, a inspiração foi buscada nas máscaras de carnaval, festividade tão intrínseca ao povo brasileiro. Investigando o objeto de estudo definido, percebeu-se que as máscaras de carnaval possuem a função de proporcionar mudanças de hábitos comportamentais ao seu portador, induzindo-o a apresentar-se de forma incomum ao seu cotidiano normal. As máscaras carnavalescas tem a capacidade de multiplicar a personalidade do seu portador. (MELO, 2011) A figura 1 apresenta a ideia de conceito aplicado no desenvolvimento do projeto e criação da coleção. 


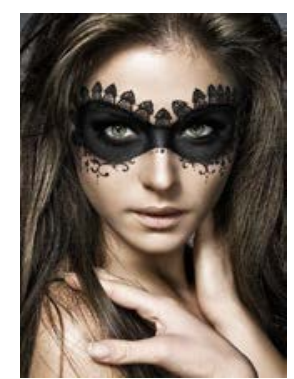

Figura 1: imagem representativa do conceito de projeto

Desta forma, foi percebida a relação possível entre o conceito escolhido e uma ferramenta amplamente utilizada em metodologias de projeto de design, a definição de um Persona. Não no intuito de criar um persona para o desenvolvimento da Coleção, mas no sentido da palavra em si. Persona é uma palavra muito usada na Psicologia, visto que na teoria de C. G. Jung, personalidade que um indivíduo apresenta aos outros como real, mas que, na verdade, é uma variante às vezes muito diferente da verdadeira. (HOUAISS, 2009)

Todos os produtos possuem envolvimento com algum tipo de tecnologia, seja na fase projetual, nos processos de fabricação ou na utilização. (GOMES FILHO, 2006) Pode ser através do modo de uso, da operacionalidade, da cognição, da ergonomia, entre outros, ou também por meio de suas características técnicas como os materiais, os mecanismos de desenvolvimento e a produção. Desta forma, a partir do conceito definido e dos requisitos de projeto, baseando-se nos quatro tipos de inovação selecionados, apresenta-se a etapa de maior diferencial da proposta da Coleção Persona.

\subsection{Materiais e Processos de Fabricação}

Os materiais, através de sua aparência e seus aspectos estéticos, remetem importâncias simbólicas e emocionais relacionadas às características culturais e sociais do usuário como, por exemplo, os metais e as gemas. (GOMES FILHO, 2006; MUSIL, 2000) A qualidade de um produto está relacionada às formas presentes no objeto que atuam como meio de comunicação como o usuário. O que faz com que o consumidor adquira um determinado produto é o conceito presente no mesmo, inclusive percepções de status proporcionadas pelo mercado. Cada produto possui seus consumidores específicos, que são conquistados através da comunicação do objeto com o usuário.

A produção industrial de joias ainda está fortemente ligada aos processos artesanais. Para que as joias produzidas industrialmente não tenham seu valor reduzido pela quantidade de exemplares é importante a interação entre design e tecnologias de produção, a fim de agregar qualidade, identidade e simbologia aos produtos. O design pode atuar contribuindo com a competitividade das empresas, agregando qualidade, promovendo redução de custos e oferecendo atributos formais e estéticos compatíveis com os consumidores. O design proporciona aos produtos uma identidade visual, valorizando as marcas através de mecanismos de comunicação.

\subsubsection{Materiais}

Visto que o objetivo está diretamente ligado às joias, nesta etapa serão apresentados os Metais e os Filmes Finos Decorativos. 


\subsubsection{Metais}

Os metais são materiais fundamentais para a produção de uma joia. As joias são constituídas de metais nobres, portanto, a cor, a dureza e a pureza podem apresentar variações de acordo coma composição das ligas. Caso o metal refletir todas as cores do espectro eletromagnético, a sua coloração será prateada, porém se o metal não refletir todas as cores do espectro eletromagnético, ele refletirá a cor que ele não absorve razão pela qual o ouro é amarelo e o cobre e avermelhado.

Os elementos mais utilizados para fabricação de joias são ouro, a prata, a platina, o paládio e o ródio, sempre utilizados na forma de ligas. Os metais nobres ou metais preciosos, são denominados assim em razão de sua raridade e ou abundância, das suas propriedades e seus potenciais de aplicações. Os materiais nobres são caracterizados por não serem atacados por ácidos ou sais, apresentam alta densidade, maleabilidade e ductilidade. Esses metais não sofrem corrosão quando expostos a agentes atmosféricos. Uma fina camada de oxidante pode ser formada na superfície do metal, porém, isso não deteriora o material. (SANTOS, 2013)

\subsubsection{Filmes Finos Decorativos: uma Proposta}

Revestimentos protetores baseados em filmes finos têm sido extensivamente empregados em diversas aplicações tribológicas, aumentando o desempenho de ferramentas de corte para usinagem e conformação frente à corrosão, desgaste e abrasão. (NARAYAN, 2005) O ramo metal-mecânico da indústria depende largamente da usinagem e conformação mecânica para a produção de componentes de engenharia. Em especial a metalurgia fina, essencial para ramos da indústria automotiva, aeroespacial, marítima e biomédica, entre outras, que tem requisitos cada vez mais restritos quanto à tolerância dimensional e as características mecânicas e tribológicas das superfícies. A figura 2 apresenta as possibilidades de acabamentos que os filmes finos podem gerar.
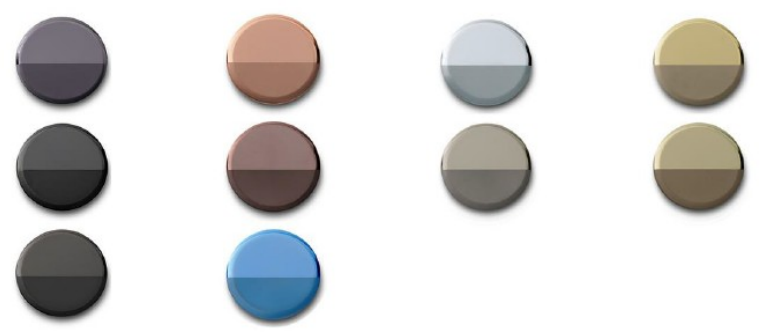

Figura 2. Acabamentos que podem ser obtidos em filmes finos.

Pode-se utilizar estes mesmos atributos citados para criar novas aplicações para estes tipos de materiais. A versatilidade do processo e o variado número de materiais que podem ser obtidos é a grande vantagem, filmes de nitreto de titânio, nitreto de silício, carbeto de tungstênio, nitreto de cromo, dentro inúmeros outros acabamentos superficiais podem ser citados. Outra vantagem é a construção desses filmes, pode-se utilizar um substrato de um material de menor custo, como exemplo o aço inox, que ainda é um material biocompatível e com custo inferior da matéria prima quando comparado o seu custo ao ouro, platina ou ainda ao paládio. 


\subsubsection{Processos de Fabricação}

As construções de joias tradicionais são realizadas pelo ourives através de suas técnicas de fundição, serra, soldagem, limagem e muitas outras. $O$ ourives ajusta a peça de forma adequada para que o cravador possa unir perfeitamente as gemas ao metal. (RODRIGUES, 2015) Como proposta para esta pesquisa apresenta-se uma nova técnica que para obtenção de filmes metálicos ou cerâmicos na fabricação de joias.

Inúmeros processos podem ser utilizados na preparação e obtenção de filmes finos decorativos, podendo ser citadas alguns como: pulverização catódica, deposição química a partir da fase vapor e deposição por descarga luminescente. Alterações nas condições de deposição produzem filmes com diferentes propriedades. Um método promissor para a produção de filmes é por PVD, utilizando o processo de pulverização catódica magnetrônica (magnetron sputtering). Este método oferece múltiplas vantagens além de ser largamente aceito na indústria por trabalhar em baixas temperaturas, ocasionar a formação de uma quantidade irrelevante de impurezas depositadas (ecologicamente limpo), além de utilizar gases inertes (argônio e nitrogênio) durante seu processamento. (MATTOX, 1998)

Aplicação de filmes finos decorativos de diferentes materiais cerâmicos apresentam múltiplas variedades de tonalidade através do processo de Deposição Física de Vapor do inglês Physical Vapor Deposition (PVD). Vale lembrar que este processo dispensa os tradicionais banhos químicos que estão relacionados com problemas ambientais de descarte de resíduos, o PVD por ser uma técnica limpa demonstra grandes possibilidades de aplicações no setor joalheiro. Os filmes finos depositados na superfície das peças proporcionam alta resistência a danos causados por possíveis impactos, desgastes e atrito. (MATTOX, 2003)

A Figura 3 representa o processo de obtenção dos filmes decorativos via rota física. O método de Magnetron Sputtering consiste em empregar um campo magnético próximo a região do alvo, com a finalidade de aprisionar elétrons secundários gerados na câmara, as linhas de campo magnético que se fecham em frente ao alvo, aumentam a ionização do gás nesta região. Desta forma há o bombardeamento do alvo, ejetando átomos do mesmo, os alvos podem ser dos mais distintos materiais metálicos, o sistema ainda pode ser utilizado para obtenção de filmes cerâmicos, estes por sua vez apresentam o maior interesse no trabalho em questões, devido ao fator destes filmes apresentarem alta resistência ao atrito. (KRUG, 2000)

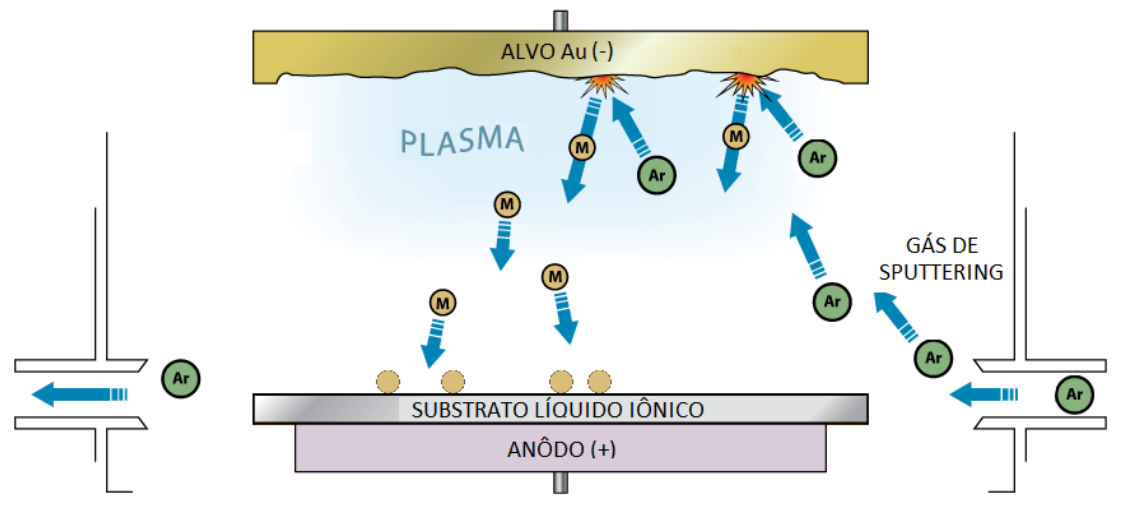

Figura 3. Esquema para deposição por Sputtering. 
O processo de PVD consiste na remoção de átomos ou moléculas de uma fonte sólida (alvo), que por diferença de potencial são conduzidos até o substrato. No momento em que os átomos depositam no substrato ocorre a nucleação, coalescência e formação do filme fino. Este processo de PVD é realizado em uma câmara de vácuo que possui gases a baixas pressões, que formam o plasma. A aplicação de um potencial elétrico no alvo causa a formação do plasma (íons positivos e elétrons) e o consequente bombardeio do alvo. Se o plasma que produz a pulverização contém espécies reativas $\left(\mathrm{N}_{2}, \mathrm{O}_{2}\right)$, podem ocorrer reações químicas formando diferentes compostos, como por exemplo, $\mathrm{TiN}_{1} \mathrm{TiO}_{2}, \mathrm{Si}_{3} \mathrm{~N}_{4}$. (ZAMBOM, 2009)

Cabe ressaltar, que os processos tradicionais de lapidação, usinagem, cravação, gravação e acabamentos, não são eliminados, mas sim podendo ser adicionados para conferir maior valor ao produto final evitando os banhos químicos e abrindo uma gama de possibilidades quando se fala em diferentes e inovadores materiais.

\section{CONCLUSÃO}

Como resultado apresenta-se a coleção e seus aspectos mais detalhados. Primeiramente um quadro síntese sobre os materiais e processos indicados, os desenhos técnicos que servem de dimensionamento, as renderizações dos modelos finais escolhidos para anel e brinco e por fim a visualização do mockup desenvolvido referente à etapa final de um projeto de design, restando apenas a etapa de inserção de mercado com o produto definitivo.

Ressaltam-se como diferenciais do resultado apresentado: i. Em relação à inovação: Aplicação de filmes finos decorativos de diferentes compostos cerâmicos, com múltiplas variedades de tonalidade através do processo de Deposição Física de Vapor do inglês Physical Vapor Deposition (PVD). Vale lembrar que este processo dispensa os tradicionais banhos químicos que estão relacionados com problemas de descarte de resíduos. É uma técnica limpa. ii. Quanto à qualidade: Os filmes finos depositados na superfície das peças proporcionam alta resistência à danos causados por possíveis impactos, desgastes e atritos. iii. À identidade Cultural Brasileira: A Coleção Persona teve suas formas inspiradas nas máscaras carnavalescas, acessórios utilizados nas festas de Carnaval, evento de forte identificação da cultura brasileira. iv. E por fim, em relação à cor: A cor preta representa o requinte e a sofisticação. É signo de nobreza, elegância e seriedade. (FARINA, 2011)

Ainda como resultado verifica-se as quatro oportunidades de Inovação escolhidas como base para o desenvolvimento do projeto, e percebe-se que de acordo com o que foram apresentados de diferenciais, também podem ser indicados para cada uma das esferas os seguintes resultados positivos: i. Inovação na sustentabilidade: O processo Physical Vapor Deposition (PVD) é uma técnica limpa que descarta os banhos químicos, relacionados com problemas de descarte de resíduos da mesma forma que a inovação proposta. ii. Inovação na Qualidade Formal-Estética: Tratamento de superfície em carbonitreto de titânio através do processo Physical Vapor Deposition (PVD). Os filmes finos depositados sobre às peças proporcionam alta resistência à danos causados por impactos, desgastes e atritos - também, da mesma forma que a qualidade destacada anteiormente. iii. Inovação na aplicabilidade de novos materiais: Uso de Aço inoxidável e Carboneto de Titânio. iv. Inovação do 
processo de fabricação: Fresamento das peças em aço inoxidável; Aplicação superficial de filmes finos decorativos através do processo Physical Vapor Deposition (PVD).

\subsection{Coleção}

A coleção proposta conta com conjunto de brincos e anel. A figura 4 apresenta quadro síntese dos materiais e processos indicados para o desenvolvimento e produção da coleção.

\begin{tabular}{|c|c|}
\hline MATERIAIS & PROCESSOS \\
\hline $\begin{array}{l}\text { AçO INOXIDÁVEL } \\
\text { Liga metálica }\end{array}$ & $\begin{array}{l}\text { FRESAMENTO } \\
\text { O fresamento é um processo de usinagem no qual são retirados excessos de material a fim de } \\
\text { proporcionar forma e acabamento ao objeto. }\end{array}$ \\
\hline $\begin{array}{l}\text { CARBONITRETO DE TITÂNIO } \\
\text { Revestimento cerâmico }\end{array}$ & $\begin{array}{l}\text { PHYSICAL VAPOR DEPOSITION - PVD } \\
\text { O Physical Vapor Deposition (PVD) é um processo de deposição de filmes finos (podendo ser } \\
\text { metálicos ou cerâmicos) na superfície de um objeto por meio de vaporização. }\end{array}$ \\
\hline $\begin{array}{l}\text { ÔNIX } \\
\text { Gema }\end{array}$ & $\begin{array}{l}\text { CRAVAÇÃO } \\
\text { O processo de cravação é a união da gema ao metal. É um processo manual que requer a } \\
\text { utilização de ferramentas específicas. }\end{array}$ \\
\hline
\end{tabular}

Figura 4: Quadro síntese de materiais e processos.

Foram desenvolvidos desenhos detalhados à mão e em softwares específicos de design para modelagem 3D para a visualização do modelo de anel e brinco definidos, conforme a figura 5 .

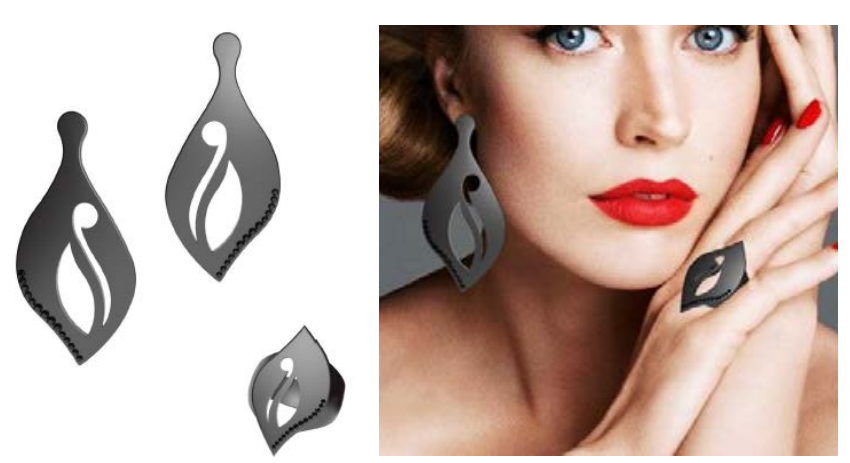

Figura 5: Renderização de modelagem tridimensional em sofware do modelo finale simulação de uso.

Posteriormente ainda desenvolveu-se um mockup como modelo visual que representa e ilustra como seria a visualização final do produto. Existem basicamente três diferenças entre modelos e protótipos: i) Escala: Os modelos trabalham em escala de ampliação ou redução, enquanto os protótipos, como conhecidos, utilizam escala 1:1. ii) Os Materiais: Nos modelos podem ser bastante variados: papel, madeira, gesso, massa de modelar, poliuretano, etc., enquanto no protótipo os materiais devem ser iguais ou equivalente ao do produto final. iii) O Funcionamento: Os modelos geralmente se destinam ao estudo da forma, não contendo elementos funcionais enquanto nos protótipos essa funcionalidade deve estar disponível para ser avaliada (BAXTER, 2011). A figura 6 apresenta o modelo do resultado da coleção. 


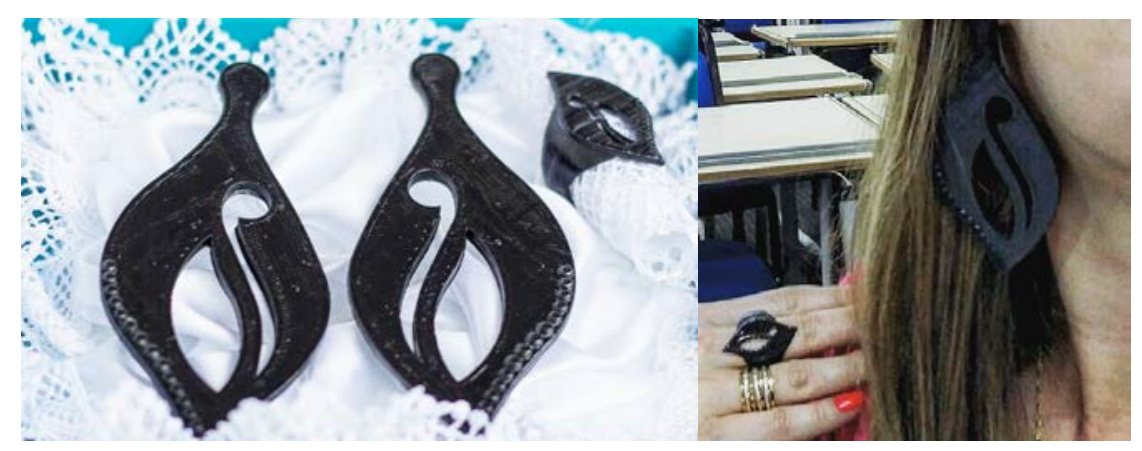

Figura 6: Modelo tridimensional de brinco e anel - Coleção Persona

A figura demonstra as questões apresentadas que relatam a diferença entre mockup e protótipo, deixando claro que as questões de escala e funcionalidade estão presentes no modelo produzido, o que possibilita a verificação que os objetivos iniciais foram atingidos. Compreende-se que o modelo apresentado não se trata de um protótipo por não ser do material indicado, mas que em relação às funcionalidades e escala se enquadrariam como um. O diferencial de fato é relacionado ao material, o que demonstra a importância de desenvolver um protótipo, mesmo que na teoria e em testes a aplicabilidade do material para a função e o produto propostos já tenha sido comprovada.

\subsection{Trabalhos Futuros}

As etapas da construção da coleção estão na Figura 8, que permite a visualização da situação atual do projeto.

\section{Executado}

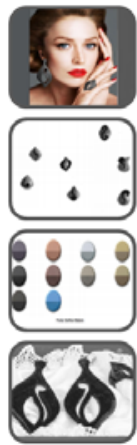

Desenvolvimento da coleção

Viabilidade do Material

Viabilidade do Processo

Mockup do modelo

\section{Previsto}

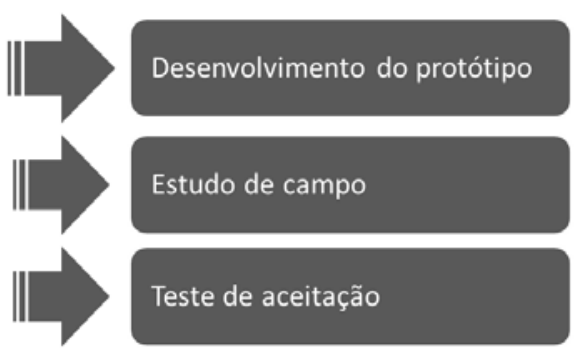

Figura 8: Etapas executadas e previstas no projeto experimental realizado

As etapas executadas englobam todas de experimentação necessárias à viabilidade do projeto, porém percebe-se a necessidade de protótipo, realização de estudo de campo para demais aplicações e teste de aceitação. $O$ teste é proposto devido à questão de cultura, status e preciosidade tão inerentes ao tema de joias.

Pode-se considerar que a proposta de projeto experimental atingiu seus objetivos por ter sido realizada dentro dos prazos estipulados e contemplando todos os quesitos pré-estabelecidos. Verifica-se a importância da experimentação de materiais já conhecidos em aplicações de usabilidade diferenciadas, como no caso apresentado. As inúmeras possibilidades que devem ser descobertas na área seguem a 
mesma lógica de testes. Por fim, considera-se que a intercambialidade possível quando se trata de uso de materiais em produtos como joias fornece base de variações considerável para novos estudos e projetos.

\section{REFERÊNCIAS}

BAXTER, Mike. Projeto de produto: guia prático para o design de novos produtos. São Paulo: Blucher, 2011

BONSIEPE, Gui. Design, Cultura e Sociedade. São Paulo: Blucher, 2011.

GOLA, Eliana. A joia: história e design. São Paulo: Editora Senac São Paulo, 2013.

GOMES FILHO, João. Design do objeto: bases conceituais. São Paulo: Escrituras Editora, 2006.

HENRIQUES, Hécliton Santini. Design Brasileiro de Joias: construção de uma identidade. Brasília: IBGM, 2012. Disponível em: < http://novo.infojoia.com.br/uploads/arquivos/file/b7703-786-

Catalogo_Premio2012.pdf> Acesso em: 15 Mar. 2015.

HENRIQUES, Hécliton S. BARRETTO, Luiz. Fruição. IBGM e SEBRAE, 2014

HOUAISS. Dicionário Eletrônico da Língua Portuguesa. Editora Objetiva, 2009.

IBGM - Instituto Brasileiro de Gemas e Metais Preciosos. Design Brasileiro de Joias: construção de uma identidade. Brasília: IBGM, 2012. Disponível em: < http://novo.infojoia.com.br/uploads/arquivos/file/b7703-786-

Catalogo_Premio2012.pdf> Acesso em: 13 Abr. 2015

LESKO, Jim. Design Industrial: materiais e processos de fabricação. São Paulo: Edgard Blücher, 2004.

LISBÔA, Maria da Graça Portella. Design e Qualidade: uma análise do processo produtivo de ourivesaria. Dissertação apresentada ao curso de mestrado da Universidade Federal de Santa Maria. Mai. 2009. Disponível em: <

http://cascavel.ufsm.br/tede/tde_busca/arquivo.php?codArquivo=2640> Acesso em: 28 Abr. 2015.

LÖBACH, Bernd. Design Industrial - Bases para a configuração de produtos Industriais. São Paulo: Editora Blucher, 2001.

MELO,Carlos de Golveia. Prolixidade do Funcionamento de Máscara ou do Efeitomáscara. Universidade de Lisbôa, 2011.

MORRIS, Richard. Fundamentos de design de produto. Porto Alegre: Bookman, 2010.

MUSIL, J. Hard and Superhard nanocomposite coating. Surface and Coatings Technology, v. 125, 2000.

NEGRÃO, Celso. Design de embalagem: do marketing à produção/ Celso Negrão, Eleida São Paulo: Novatec Editora, 2008. Camargo. São Paulo: Novatec Editora, 2008.

ONO, Maristela Misuko. Design, Cultura e Identidade, no contexto da globalização.

Revista Design em Foco v. I no 1. Jul/Dez 2004. Disponível em: < http://www.redalyc.org/articulo.oa?id=66110107> Acesso em: 28 Mar. 2015. 
PRENDINI, Angela Nazareth. Em depoimento para o livro: Joias: fundamentos, processos e técnicas, p.292. Autora: Rita Santos. Rio de Janeiro: SENAC Nacional, 2013. PREVIEW DESIGN DE JOIAS E BIJUTERIAS. FRUIÇÃO 2015. Ago. 2014.

SANTOS, Rita. Joias: fundamentos, processos e técnicas. Rio de Janeiro: SENAC Nacional, 2013.

STRALIOTTO, Luiz Marcelo. Ciclos: Estudo de casos de ecodesign de joias. Dissertação de mestrado apresentada na Universidade Federal do Rio Grande do Sul. Porto Alegre, 2009. Disponível em: <http://www.lume.ufrgs.br/handle/10183/18600> Acesso em: 26 Mar. 2015.

VICENTINI, Murilo. Designer de joias: uma profissão antiga e de muito luxo. SENAC, Ago. 2014. Disponível em: < http://www.rj.senac.br/noticias/designer-de-joias-umaprofissao-antiga-e-de-muito-luxo> Acesso em: 15 Mar. 2015. 